\title{
Accelerating action to end child marriage in Bangladesh-Project brief
}

Population Council

Follow this and additional works at: https://knowledgecommons.popcouncil.org/departments_sbsr-pgy

Part of the Demography, Population, and Ecology Commons, Family, Life Course, and Society Commons, International Public Health Commons, and the Maternal and Child Health Commons How does access to this work benefit you? Let us know!

\section{Recommended Citation}

"Accelerating action to end child marriage in Bangladesh-Project brief." Dhaka: Population Council, 2019. 


\section{ACCELERATING ACTION TO END CHILD MARRIAGE IN BANGLADESH}

Duration
Jan 2017 - Dec 2020

\section{BACKGROUND}

In 2016 the Population Council completed the Bangladeshi Association for Life Skills, Income, and Knowledge for Adolescents (BALIKA), a four-arm randomized controlled trial (RCT) that rigorously evaluated three community-based alternative skillbuilding strategies. BALIKA reduced child marriage, reduced school dropout, improved health knowledge and health seeking behaviors, and improved gender normative attitudes. Building on the experience of BALIKA, Accelerating Action to End Child Marriage is another program, evaluated with an RCT, being implemented to generate evidence of an adolescent skills-building program in reducing child marriage. The unique feature of the additional community engagement component of this program identifies the best strategy for engaging the community to reduce child marriage by testing three alternative community approaches against each other. This program is part of UNFPA-UNICEF Global Program to Accelerate Action to End Child Marriage (GPECM).

\section{WHAT WE DO}

The Population Council is partnering with UNFPA and Ministry of Women and Children Affairs (MoWCA) to delay marriage. The project works to empower girls with life-skills, livelihood and gender awareness trainings, and engaging communities to address normative drivers of child marriage. Council's role is to:

$\Rightarrow$ Design and implement baseline, midline and endline surveys.

$\Rightarrow$ Develop and implement an effective M\&E system.

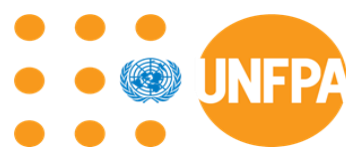

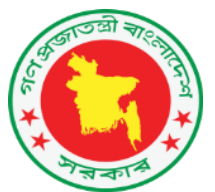

Bangladesh ranks among the five countries with the highest rate of child marriage in the world with

$59 \%$ girls marrying before 18 .

Community norms and values are among the underlying factors that support the practice of child marriage in Bangladesh.

The project aims to identify scalable and sustainable approaches to reduce child marriage by working with the Ministry of Women and Children Affairs (MoWCA). The project offers skills-building opportunities to adolescent girls in combination with three approaches to community engagement that vary in terms of who in the community are engaged as supportive allies.

\section{COMMUNITY COMPONENT}

$\Rightarrow \quad$ One that engages only by reaching adolescents but does not otherwise engage community;

$\Rightarrow \quad$ One that reaches adult male support groups in addition to adolescent girls; and

$\Rightarrow \quad$ One that reaches adult female support groups in addition to adolescent girls. 


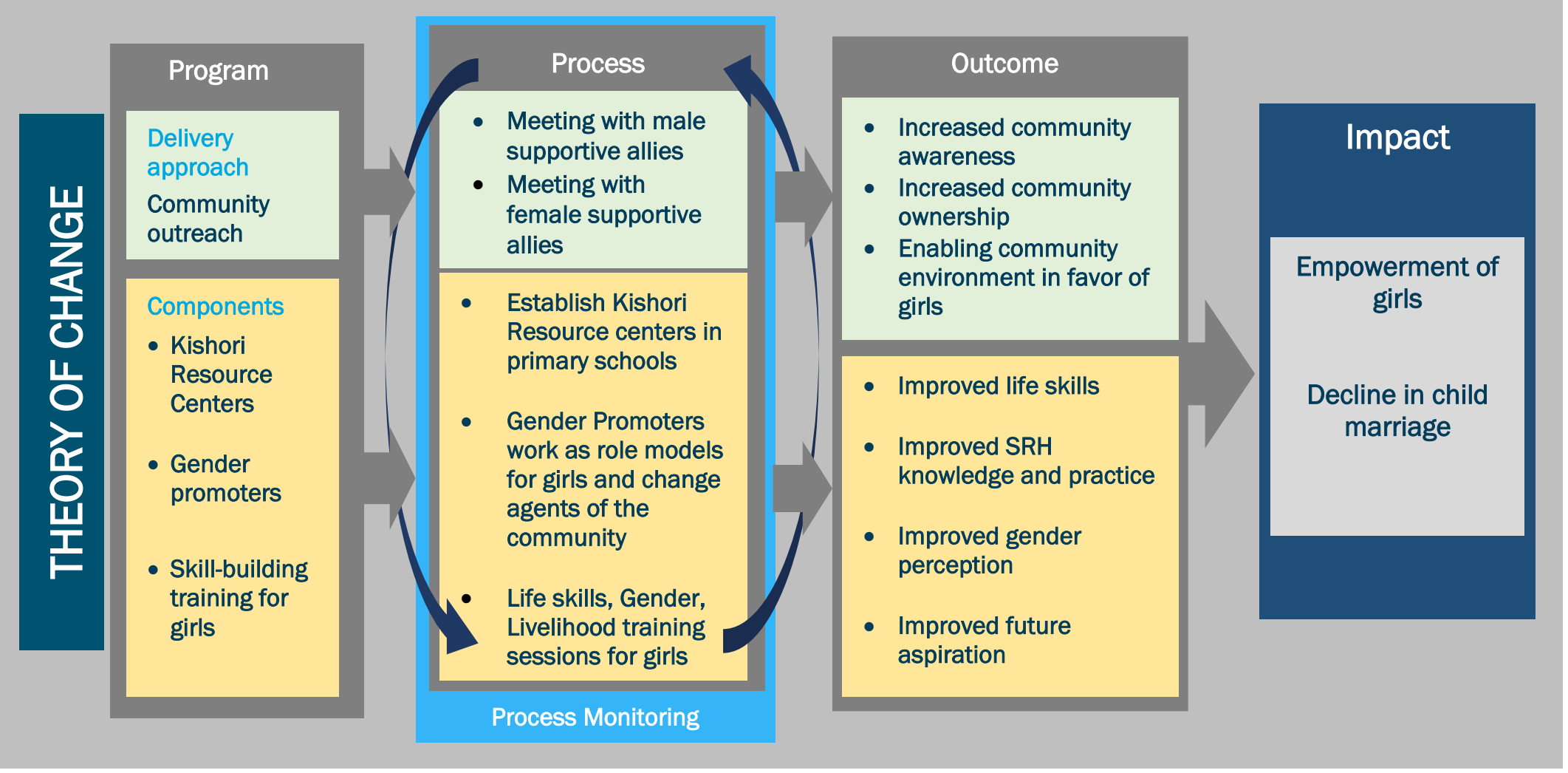

\section{HOW WE WORK}

\section{Skills training intervention}

The skill-building intervention includes 17 hours of life skills curriculum, 19 hours of gender awareness curriculum and 28 hours of livelihoods curriculum. The Curriculums of this project are reproduced based on the curriculums of BALIKA.
Each adolescent group has 30 members containing both married and unmarried and in-school and out-ofschool girls. Each group receives equivalent hours of curriculum-based training; however, some parts of the curriculum are customized to be appropriate for age, and marital status. The program will run for a period of 12 months for each cohort.

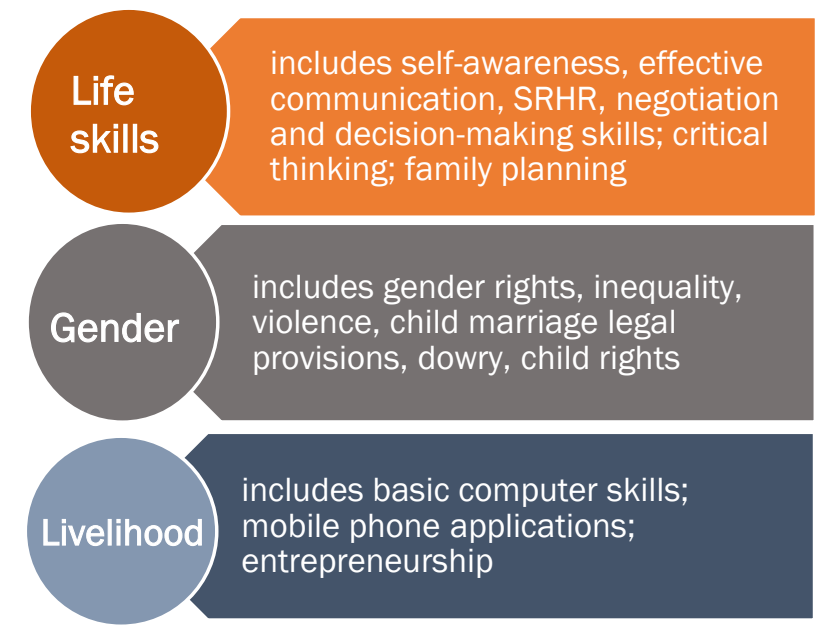

Kishori Resource Centers

Skill-building intervention for girls takes place in 72 union-based Kishori Resource Centres (located in primary schools). Each center has laptops, internet connection, and associated reading materials to run the sessions for 2 adolescent groups.

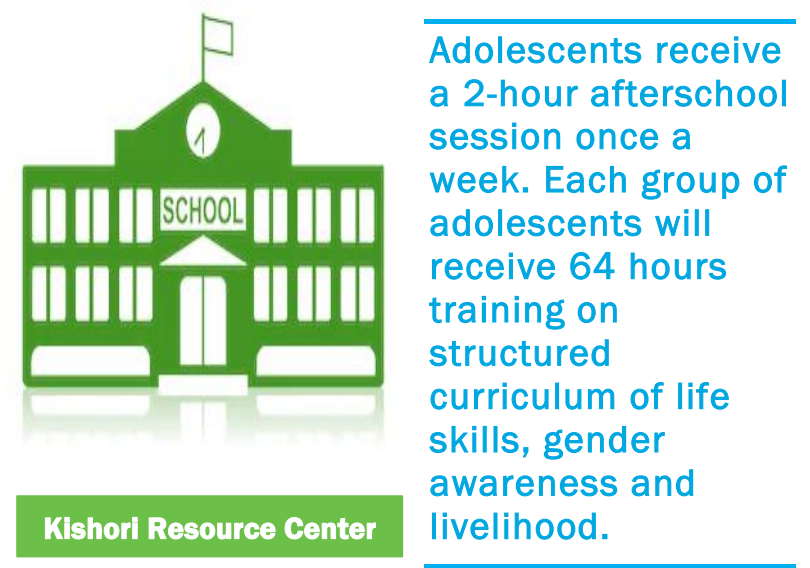

Gender Promoters

Gender Promoters (GP) are the key person to implement project activities. 36 young female graduates aged 25-30 years known are recruited from the intervention locality by MoWCA as mentors to the adolescents to serve as GPs. 
Each GP is responsible to implement project activities in 2 unions. Their primary responsibility includes training sessions for girls at the Kishori Resource Centers and conducting community outreach activities. GPs take various trainings to become mentors, session leaders and role models for girls. GPs receive training on life skills, gender and livelihood curriculum as well as training on conducting community outreach activities, session facilitation and skills on basic computer. With their level of capacity and engagement GPs act as change-makers within communities, specially in rural areas. As mentors, GPs become empowered and financially independent as well.

\section{Community outreach}

Engagement with the community forms the basis of long-term sustainability of the program. Community engagement meetings discuss issues relating to child marriage such as schooling, gender perception, safety security and livelihood for girls with the gatekeepers of the community as identified by the girls as their supportive allies. These gatekeepers can work as advocates against child marriage and ensure local ownership of the project.

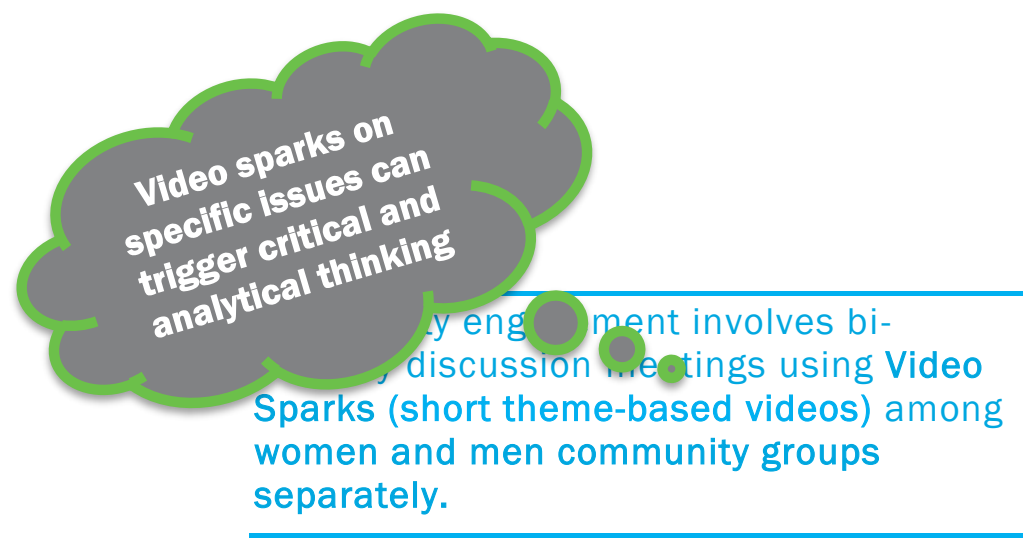

Community engagement meetings are conducted with:

\section{$\Rightarrow$ adult male support groups \\ $\Rightarrow$ adult female support groups}

Outreach activities conducted separately with men and women group identifies diverse benefits or challenges of community involvement in achieving program goals. Working with adult men may be effective for promoting choice for girls where patriarchal barriers dominate the practice of child marriage. On the

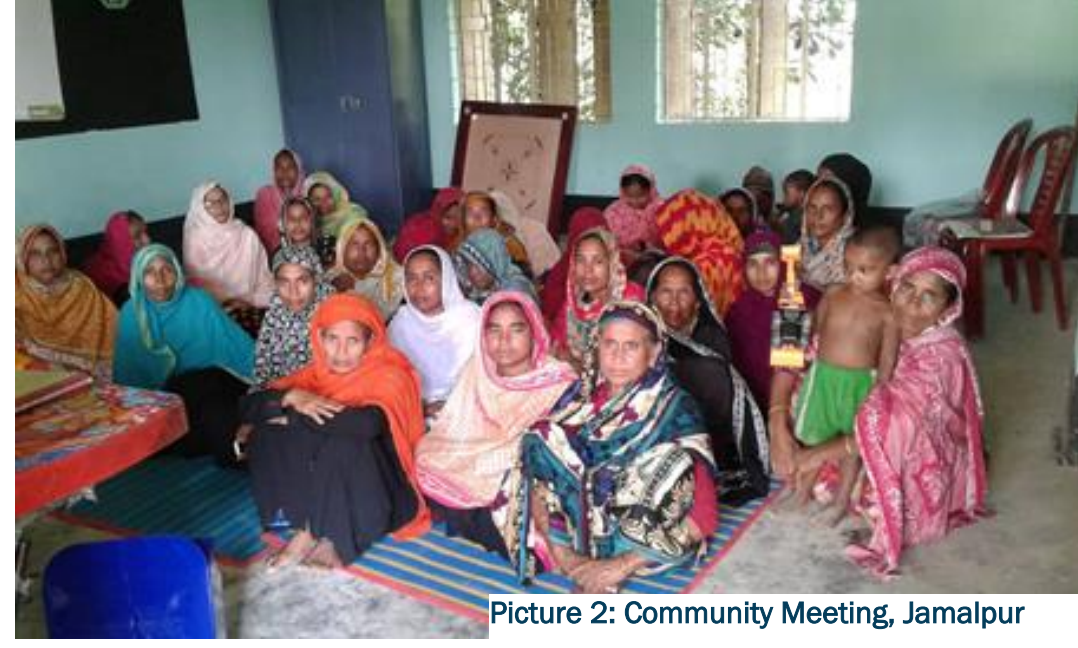

other hand, engaging adult women may be more effective because they have more natural affinity and sympathy with adolescent girls and can become more effective advocates for girls in the community.

\section{Kishori Resource Center management committee}

The project also forms a group known as Kishori Resource Center management committee that will be involved in both Kishori Resource Center management and advocacy for girls in the community to ensure local ownership of the project and to harmonize activities. Management committee is composed of local UP Chairman, member: both male and female, parents, schoolteachers and locally influential people. GPs convene meetings with this committee on regular intervals.

\section{Program monitoring}

The Council developed a real-time online/offline monitoring system to visualize data through dashboard and to enable data reporting to multiple levels. SurveyCTO, a web-based software is used to create dashboards for session and activity monitoring. Attendance of the girls during after-school sessions and quality of the sessions are monitored by the dedicated project staff.

\section{Reference}

1. Bangladesh Bureau of Statistics (BBS) and United Nations Children's Fund (UNICEF). (2015). Multiple Indicator Cluster Survey 2012-2013 Progotir Patheyh.

2. Amin et al. 2018. Skills-building programs to reduce child marriage in Bangladesh: A randomized controlled trial. Published in Journal of Adolescent Health. 